\title{
A lógica da amizade na comunidade fraterna como constituição do político-democrático: um diálogo entre Agamben e Derrida
}

\author{
The logic of friendship in the fraternal community as a political-democratic \\ constitution: a dialogue between Agamben and Derrida
}

\author{
Maiquel Angelo Dezordi Wermuth* \\ Fabiana Marion Spengler ${ }^{* *}$
}

\section{Resumo}

\begin{abstract}
Partindo do filme "A excêntrica família de Antônia", o presente texto tem como tema a amizade na comunidade fraterna embasado nos textos de Jacques Derrida e Giorgio Agamben. O problema que orienta esta pesquisa é: quais são os limites e possibilidades das tentativas de se recuperar o político "dentro" e para "a" comunidade, repensando-o e reconstruindo-o junto com a democracia? A hipótese de resposta ao problema apresentado aponta que, por meio desse resgate, viabiliza-se um deslocamento da amizade da esfera privada, da intimidade - local para o qual foi banida especialmente pelo cristianismo, que alargou a amizade e a esvaziou do político -, para o mundo, o espaço público, a comunidade. Partindo do problema de pesquisa e da hipótese, o objetivo do texto é apresentar, a partir da ótica dos dois filósofos contemporâneos acima indicados, as diferentes concepções de amizade, comunidade e fraternidade, e sua importância para a delimitação do político e da democracia. A metodologia de abordagem utilizada foi a fenomenológicohermenêutica, de Martin Heidegger.
\end{abstract}

Palavras-chave: Comunidade. Amizade. Fraternidade. Política. Democracia.

\section{Abstract}

Starting from the film "The eccentric family of Antonia" the present text has the theme of friendship in the fraternal community from the texts of Jacques Derrida and Giorgio Agamben. The problem that guides this research is: what are the limits and possibilities of attempts to recover the political "inside" and "the" community, rethinking and rebuilding it along with democracy? The hypothesis of answer to the problem presented indicates that, through this rescue, it is possible to shift the friendship from the private sphere, from the local intimacy to which it was especially banished by Christianity that extended the friendship and emptied it of the politician - to the world, the public space, the community. Starting from the problem of research and hypothesis, the objective of the text is to present, from the perspective of the two contemporary philosophers above, the different conceptions of friendship, community and fraternity and their importance for the delimitation of politics and democracy. The methodology of approach used was the phenomenological-hermeneutic of Martin Heidegger.

Keywords: Community. Friendship. Fraternity. Politics. Democracy.

\section{Introdução}

No filme "A excêntrica família de Antônia" (1995) - co-produção holandesa/belga/inglesa ganhadora do Oscar de Melhor Filme Estrangeiro - a diretora, Marleen Gorris, retrata a trajetória de Antônia, mulher

Doutor em Direito pela Universidade do Vale do Rio dos Sinos - UNISINOS - RS. Professor dos cursos de graduação em Direito da UNISINOS e UNIJUÍ. Professor do Curso de Mestrado em Direitos Humanos da UNIJUÍ. Coordenador da Rede de Pesquisa em Direitos Humanos e Políticas Públicas - REDIHPP. Líder do Grupo de Pesquisa Biopolítica e Direitos Humanos (certificado pelo CNPq). ljuí-RS-Brasil. E-mail: madwermuth@ gmail.com.

Pós-doutora em Direito pela Università degli Studi di Roma Tre, em Roma na Itália, com bolsa CNPq (PDE). Doutora em Direito pelo programa de Pós-Graduação stricto sensu da Universidade do Vale do Rio dos Sinos - UNISINOS - RS, mestre em Desenvolvimento Regional, com concentração na área Político Institucional da Universidade de Santa Cruz do Sul - UNISC - RS, docente dos cursos de Graduação e Pós Graduação lato e stricto sensu da UNISC, Coordenadora do Grupo de Pesquisa "Políticas Públicas no Tratamento dos Conflitos" vinculado ao CNPq, Coordenadora da Rede de Pesquisa em Direitos Humanos e Políticas Públicas - REDIHPP. Santa Cruz do Sul-RS-Brasil. E-mail: fabiana@unisc.br 
que assume o status de "estrangeira" quando retorna, acompanhada da filha, ao pequeno vilarejo onde nasceu, por ocasião da morte de sua mãe, vinte anos depois de ter partido.

O "estrangeirismo" de Antônia se evidencia, principalmente, a partir do fato de que ela não compartilha dos hábitos da maioria dos habitantes do local, o que a coloca numa posição de contestação. E é justamente essa condição - de "estranha", alien - que faz dela uma mulher mais forte, segura e disposta para arrostar várias manifestações de preconceito da população do vilarejo - notadamente no que diz respeito à dificuldade para aceitar e conviver com o "diferente".

Ao longo do filme, são apresentadas diversas personagens que são encontradas por Antônia em uma situação de vulnerabilidade por serem consideradas "anormais". A histórica centra-se, principalmente, em DeeDee (uma portadora de necessidades especiais que é reiteradamente violentada pelo próprio irmão), Boca Mole (explorado como mão-de-obra barata para a realização de trabalho braçal) e Dedo Torto (um filósofo pessimista).

Ao longo do filme, Antônia vai acolhendo em sua casa todas as personagens consideradas "estranhas" pelos moradores do vilarejo, constituindo, assim, a sua "excêntrica família". Ao assim agir, Antônia, reflexamente, desativa de dispositivos de poder em operação na localidade antes de sua chegada. Por outro lado, Antônia também representa, na sua trajetória, a concretude de algumas categorias, tais como amizade e fraternidade (que ela distribuía a todos os excluídos que passaram a integrar sua lista de protegidos) e comunidade (formada por seus protegidos/excluídos).

Para os efeitos do presente estudo, compreende-se que a história da constituição da "excêntrica família" de Antônia permite uma aproximação com o percurso filosófico de muitos autores ${ }^{1}$ - dentre eles, Jacques Derrida e Giorgio Agamben - que debatem a amizade e a comunidade como ponto central de suas obras. Coloca-se, então, o problema que orienta esta pesquisa: quais são os limites e possibilidades das tentativas de se recuperar o político "dentro" e para "a" comunidade, repensando e reconstruindo-o junto com a democracia? Parte-se da hipótese de que, por meio desse resgate, viabiliza-se um deslocamento da amizade da esfera privada, da intimidade - local para o qual foi banida especialmente pelo cristianismo, que alargou a amizade e a esvaziou do político -, para o mundo, o espaço público, a comunidade.

Nesse sentido, o objetivo do texto é apresentar, a partir da ótica dos dois filósofos contemporâneos acima indicados, as diferentes concepções de amizade, comunidade e fraternidade, e sua importância para a delimitação do político e da democracia.

No que tange à estrutura do texto, em um primeiro momento, será abordada a questão da amizade e suas relações com a fraternidade a partir da obra de Jacques Derrida, para, na sequência, investigar o tema da "comunidade que vem", tal como proposto pela obra de Giorgio Agamben.

Para a concretização da pesquisa, a metodologia de abordagem utilizada foi a fenomenológicohermenêutica, de Martin Heidegger. A fenomenologia hermenêutica busca relacionar o sujeito (pesquisador) com o objeto (pesquisa) por entender que não há como o pesquisador situar-se para além do objeto pesquisado, não podendo elevar-se para fora dele; estando, dessa forma, relacionado com o objeto.

\section{A amizade e suas relações com a fraternidade em Jacques Derrida}

Poder-se-ia, de modo geral, explicar a história da fraternidade nos sistemas sociais como uma história atravessada e assinalada, a todo momento, por contínuos movimentos paradoxais, de diferenciações crescentes da comunidade e de crescentes tendências de recomposições unitárias. Isto explica o porquê do essere-in-comune dos irmãos, que condividem o nascimento, vir representado como o lugar da paz e da guerra, da concórdia e do conflito, então, como o lugar da ambivalência por excelência. Representa, assim, tanto o espaço da solidariedade como aquele da inimizade e da rivalidade, aquele de Antígona e

É possível citar aqui Maurice Blanchot, Michel Foucault, Gilles Deleuze, Felix Guattari, Jean-Luc Nancy. Porém, nesse momento, o debate estará centrado nas obras de Jacques Derrida e Giorgio Agamben. 
de Caim. A expressão bíblica "irmãos inimigos" pode ser entendida tanto no sentido que se é inimigo, não obstante seja irmão, quanto de que se é inimigo justamente por ser irmão.

Nestes termos, a obra Políticas da Amizade $^{2}$ apresenta-se como um texto de cunho evidentemente político, uma vez que propõe o debate sobre a (im)possibilidade de uma nova experiência da amizade, o que por si só representa um desafio às formas tradicionais de pensar o político. ${ }^{3}$ Assim, a amizade que pode ser revista e, quem sabe, reconstruída, partindo do texto de Derrida, como um exercício do político enquanto forma e meio de re-traçá-lo e de re-inventá-lo.

A filosofia de Derrida ressalta, no pensamento iluminista de Kant, o respeito enquanto condição para a verdadeira amizade. Kant (1986) confere originalidade a esse conceito, ligando-o a outra palavra importante no contexto da amizade: responsabilidade. Desse modo, percebe-se que não existe respeito, sem uma visão clara, para a qual é necessária certa distância e espaço próprio; da mesma forma, não pode haver responsabilidade sem resposta, sem comunicação, sem esse receber que toma o tempo, que faz perdê-lo para depois ganhá-lo.

Assim, de Kant a Derrida, baseando-se em Aristóteles (1996), respeitar um amigo não é necessariamente respeitar a lei. A amizade existe somente quanto à pessoa e não quanto à lei. Esta última pode apenas ser causa do respeito moral (DERRIDA, 2003, p. 258). Derrida encontra nos textos aristotélicos, e com base neles trabalha, a ligação entre o justo, a amizade e a divisão comunitária. Nesse contexto, Derrida recorta duas consequências da amizade: a) ela é uma relação irredutível ao instrumento (dimensão técnica); b) ela se destina à democracia. ${ }^{4}$ Não que isso seja firme como uma lei, mas seria uma tendência, uma relação proporcional, porque há mais coisas comuns lá onde os cidadãos são iguais, e a partilha comunitária implica mais lei, mais contrato, mais convenção. Logo, a democracia é mais favorável à amizade do que a tirania. A politeia é coisa de irmãos (ALBORNOZ, 2010, p. 144-145).

Assim, gradativamente, o amigo aparece nos discursos da amizade na figura do irmão. A partir de Aristóteles, a amizade democrática constitui-se numa relação de fraternização: a amizade é, em princípio, democrática, justamente por ser fraternal. Apesar dos grandes discursos da amizade terem vinculado o irmão-amigo à democracia, à justiça, à virtude e à razão política, essa identificação do irmão com o amigo, ou o inimigo, não é evidente (ORTEGA, 2000, p. 60).

Porém, o ideal universalista da fraternidade exclui, em princípio, qualquer inimizade ou hostilidade, o que é, sem dúvida, uma utopia. Não se deve esquecer que as hostilidades mais violentas, amargas e intensas acontecem com mais frequência entre indivíduos que apresentam semelhanças étnicas, ideológicas ou que estão aparentados, do que entre estranhos. Justamente por isso o suposto universalismo do discurso fraternalista encerra uma lógica particularista que possibilitou, historicamente, o surgimento de políticas nacionalistas, xenófobas e populistas (ORTEGA, 2000, p. 63-64).

Derrida pondera que é talvez impossível identificar o conceito de fraternidade com o de philia dos gregos - se é que sabemos o que era para os gregos philia -, mas ainda é problemático aproximá-lo de freundschaft, friendship ou amitié nas línguas modernas. Nessa mesma linha de raciocínio, Eligio Resta reforça que "la construzione simbolica di un'identità percepita attraverso la minacia (non estranea, peraltro, all'intera storia dell'Europa) registra um progressivo accostamento tra la fraternità e il concetto greco di amicizia (philía)" (RESTA, 2007, p. 591).

É nesse sentido que a proposta de Derrida busca desmascarar todos os discursos filosóficos da amizade como discursos da fraternidade enquanto movimento de delimitação, propondo pensar a amizade além dela. O que pretende Derrida é apontar a ligação entre amizade, fraternidade e democracia. Sua proposta é apresentar uma nova política da amizade (im-possível?). Para alcançar tal intento, ele busca

\footnotetext{
Derrida (2003).

"Raramente se anuncia o conceito do político sem alguma aderência do Estado à família, sem aquilo a que chamamos uma esquemática da filiação: a cepa, o género ou a espécie, o sexo (Geschlecht), o sangue, o nascimento, a natureza, a nação - autoctonia ou não, telúrica ou não." (DERRIDA, 2003, p. 10).

4 Nesse ponto, Derrida faz a vinculação entre fraternidade e democracia dizendo que esta última raramente foi determinada sem a confraria ou a fraternidade.
} 
desconstruir a ligação entre a amizade e fraternidade, presente em todos os discursos, para criar o espaço de uma nova amizade e uma nova democracia para além da fraternidade, para além da fraternização. Uma "democracia por vir", que faça jus a essa amizade, como talvez. Uma democracia sem autoctonia e eugenia, livre de suas figuras familiares e androcêntricas, sem deixar, por isso, de ser democracia. É possível? Talvez. (ORTEGA, 2000, p. 60).

A desconstrução da amizade e a busca de uma nova política da amizade que vá além da fraternidade, ou seja, além da compreensão comum de democracia, revela o perigoso "talvez" de uma (im)possibilidade. É nesse ponto que Derrida usa Carl Schmitt (1992) para ressaltar que a oposição - ou seja, a inimizade - faz e delimita o político. Não é da amizade que ele nasce, mas da existência do inimigo. Por isso, se quiséssemos fazer derivar uma política da amizade, mais do que da guerra, teríamos ainda que nos entender a respeito do que quer dizer "amigo". Ora, a significação do "amigo" não se determina senão na distinção oposicional "amigo-inimigo" (DERRIDA, 2003, p. 252).

Assim, é preciso que haja luta real para que se manifeste a lógica última da configuração política que opõe o amigo/inimigo. É na perspectiva dessa possibilidade extrema que a vida dos homens se enriquece com a sua tensão especificamente política. Um mundo no qual a possibilidade de luta tivesse sido inteiramente afastada e banida, um planeta definitivamente pacificado, seria um mundo sem discriminação do amigo/inimigo e, consequentemente, um mundo sem política. Não se poderia apreender o fenômeno político abstraindo essa possibilidade real de agrupamento em amigos e inimigos, quaisquer que sejam as consequências para a avaliação do político, de um ponto de vista religioso, moral, estético ou econômico.

O discurso de Derrida reforça o processo vertiginoso de hiperbolização ao qual se expõe a amizade e a fraternidade. Existe sempre algo mais fraternal do que o irmão, mais amigável do que o amigo, mais justo do que a justiça ou o Direito - e a medida é dada, justamente, pela imensidão, pela incomensurabilidade desse "mais". O mecanismo de hiperbolização (porque se encontra mecânica e técnica nessa regularidade) trabalha toda essa semântica entre o sentido estrito e o sentido próprio. Desse modo, a verdadeira fraternidade, a fraternidade em sentido próprio, seria a fraternidade universal, espiritual, simbólica e infinita, a fraternidade de juramento, e não a fraternidade em sentido estrito, a do irmão "natural" (como se isso alguma vez existisse), do irmão viril, por oposição à irmã, do irmão determinado, nesta família, nesta nação, nesta língua. E aquilo que aqui é relevado da fraternidade, como esquema dominante da amizade, transporta nesta, como em todos os valores associados à sua desconcertante hipérbole (DERRIDA, 2003, p. 244).

Para Derrida, os discursos filosóficos da amizade reproduziram a lógica do epitáfio. Isto significa a possibilidade de uma amizade para além da morte. A história da contínua citação atribuída a Aristóteles por Montaigne: "Ó, meus amigos, não há amigos". Assim, amar o amigo supõe o compromisso de amá-lo além da vida ou da morte. Desse modo, conforme a lógica derridiana, escavar nos discursos da amizade a lógica do epitáfio permite apontar duas questões: a) referência à simetria e à igualdade na relação de amizade; b) à temática do luto e suas implicações políticas. Por conseguinte, a amizade passa a ser o luto político pelo amigo-irmão.

Essa relação entre o amigo-irmão e entre o amigo/inimigo funda e representa, como apontado anteriormente, o político. A forma como essa relação se dá no seio da fraternidade e na elaboração de um direito fraterno é um dos temas com os quais se ocupa a obra de Eligio Resta. ${ }^{5}$

Com efeito, o direito fraterno é aquele que surge quando a igualdade irrompe no coração da soberania e parece, finalmente, realizar um projeto simbólico nascido com a modernidade, aquele do abatimento de um direito paterno, existente desde sempre, dado por Deus, da tradição, da natureza, ou seja, daqueles legados que obstaculizavam o imperativo de transformação.

Esse ponto merece especial atenção: se o direito fraterno é convencional e não violento, é importante pensá-lo perpassado pela lei da amizade, que encontra "nos processos de codificação moderna a fórmula

Essa ambivalência na figura do irmão, que pode ser também inimigo, vem sequestrada dos textos de Eligio Resta (2007, p. 588), no qual ele expõe: "l'espressione biblica: "fratelli nemici" può essere intesa tanto nel senso che si è nemici nonostante si sai fratelli, quando che si è nemici próprio perché fratelli." 
do imperativo da fraternidade diante de um jogo político, construído em cima da contraposição, conhecida, do amigo-inimigo". ${ }^{6}$ Porém a amizade não desenvolve um percurso linear entre virtude coletiva e qualidade, que "definha na relação e que oscila do plano da vida pública àquela da mais íntima esfera privada". Quanto mais a amizade perde "seu caráter de argamassa espontânea da sociedade", mais tem necessidade de ser prescrita por uma lei que contenha imperativos ético-religiosos e, principalmente, jurídicos. Assim, os amigos deixam de ser necessariamente aqueles ligados por laços fraternos e de solidariedade, uma vez que se esquivam do vínculo e da reciprocidade cotidiana, compartilhando a vida sem compartilhá-la (RESTA, 2004, p. 20-21).

A gênese da amizade se divide em contingente e transcendente, uma vez que depende do acaso e do evento em que se desenvolve, por isso a comunidade de apoio já perdeu o sentido universalista e se confinou às relações numericamente mensuráveis de uma amizade definida. Consequentemente, "somos amigos porque existem inimigos, somos amigos porque nos escolhemos para nos contrapormos a outras formas de relações impostas ou involuntárias" (RESTA, 2004, p. 31). Essas relações determinam um caráter de inclusão/exclusão à amizade, incluindo o amigo, excluindo o inimigo e tornando-se uma improbabilidade normal.

As relações havidas entre amigos e inimigos em um mesmo território vêm - de acordo com Freud em seu texto Considerações sobre la guerra y la muerte - estabelecidas dentro de cada nação, por suas regras morais, às quais os indivíduos deveriam se ajustar. Essas regras traziam grandes delimitações e uma acentuada renúncia aos instintos naturais do homem. Tais normas são consideradas a base do Estado civilizado, sendo por ele defendidas. Assim sendo, quem cumpria as normas era o amigo e quem não as respeitava, o criminoso, ou seja, quem se submetia a elas era amigo e quem as repudiava era considerado criminoso.

Discutindo a relação de pertença e a inimizade, Freud (1997) salienta que existem três tabus essenciais: os inimigos estrangeiros à tribo, os chefes estrangeiros ao grupo e o morto estrangeiro à vida. Possuindo um caráter fora dos padrões considerados normais, o poder que podem exercer esses estrangeiros sobre os indivíduos são delimitados pelo fato de que o inimigo nos mata, o chefe nos subjuga e os mortos nos assombram e chamam.

As relações de amizade/inimizade entre o cidadão e o estrangeiro possuem um vínculo estreito com a instituição da hospitalidade (xenia) que pode ser resumida como uma forma de se relacionar com os estrangeiros, incluindo uma série de obrigações e benefícios recíprocos. Tal se dá porque as leis da hospitalidade impõem restrições à própria hospitalidade. Assim, é sempre "o direito e as leis que constituem, impõem, determinam, condicionam e delimitam as relações com o estrangeiro" (ORTEGA, 2002, p. 18). Segundo Derrida (1997, p. 69 e p. 131-132), esse "devir direito da justiça", é característico das leis da hospitalidade, possuindo "a mesma predominância na estrutura do direito à hospitalidade e da relação com o estrangeiro, seja hóspede ou inimigo". Trata-se de um "modelo conjugal, paternal e falogocêntrico. É o déspota familiar, o pai, o esposo, o patrão, o dono da casa, que faz as leis da hospitalidade" (ORTEGA, 2002, p. 18).

Desse modo, o autor francês aponta para o fato de que uma lei da hospitalidade incondicional poderia exigir o rompimento com leis da hospitalidade constituídas mediante um pacto, uma aliança ou um contrato. Uma hospitalidade justa, que incita a romper com a hospitalidade como lei ou direito, pressupõe observar o estatuto social e familiar dos contratantes, bem como a possibilidade de chamá-los "por seu nome, de terem um nome, de serem sujeitos de direito, interpelados e passíveis, imputáveis, responsáveis, dotados de uma identidade nomeável, de um nome próprio" (DERRIDA, 1997, p. 27).

Portanto, constituir um pacto de hospitalidade impondo condições a ela é uma maneira de assimilar o outro, suprimindo a sua singularidade, a sua alteridade, porém "assimilar o outro" não é o suficiente, pois

\footnotetext{
"Os conceitos de amigo e de inimigo devem ser entendidos no seu sentido concreto, existencial, e nunca como metáforas ou símbolos; não se deve atenuá-los misturando-Ihes representações econômicas, morais ou outras, nem sobretudo interpretá-los psicologicamente num sentido privado-individualista, como se eles exprimissem sentimentos e tendências privadas. Esses conceitos não são nem oposições normativas e nem oposições espirituais". (DERRIDA, 2003, p. 250).
} 
é preciso que ele seja acolhido e passe a fazer parte do nosso espaço; pensar/agir de modo diverso é assimilar o outro e integrá-lo. Agir de modo diverso é não ser hospitaleiro.

No entanto, a dificuldade de integrar o outro e a postura voltada à sua assimilação é uma postura que ignora sua alteridade e que, muitas vezes, é assumida porque o estrangeiro pode destruir meu espaço, pôr em dúvida minha identidade e, até mesmo, impor sua cultura ou sua língua. Então, uma dúvida persiste: "como criar uma relação de hospitalidade que não seja imposta como assimilação ou aculturação, mas que também não seja simplesmente a ocupação de meu espaço pelo outro?” (ORTEGA, 2002, p. 20). Talvez a melhor hipótese para responder a essa questão seja a negociação constante, sem o engessamento de regras inflexíveis e pré-determinadas, na forma de um programa vazio. Segundo Derrida (1997, p. 33), justamente por isso a negociação deve ser dar a cada instante, constantemente. Assim, as regras mais adequadas devem ser inventadas a cada segundo, independentemente dos riscos envolvidos, o que se torna muito perigoso.

Quando o assunto é a hospitalidade/alteridade, o nome é uma questão fundamental. Tal se dá porque demandar o nome de alguém pressupõe atribuir uma identidade e uma responsabilidade ao estrangeiro, que responderá diante da lei e diante dos hóspedes, como uma testemunha em um tribunal. É justamente o nome que o constitui como sujeito de direito. O outro, aquele que não possui um nome, é excluído do abraço da xenia. Consequentemente, as discriminações amigo/inimigo percorrem toda a Grécia clássica mediante um código binário: amizade no interior, inimizade no exterior.

Porém, atualmente, a amizade deixou de ser o cimento da sociedade, porque se encontra encoberta pela inimizade. Não se pode perder de vista que

[...] a comunidade política é, de fato, descrita como o lugar no qual o inimigo, por convenção, não é mais interno, mas externo. O inimigo interno, por uma complexa metamorfose da semântica reservou-se o papel de 'criminoso' ou de opositor político, ou ainda, de minoria: as passagens são, obviamente, todas ricas e refinadas, e sequer são repentinas. Pressupõem que já esteja em andamento um 'contrato natural' (assim o define Michel Serres) pelo qual se 'pertence' a uma nação, e por isso são aceitas todas as suas leis (RESTA, 2004, p. 34).

O que indica a relação de pertença entre um indivíduo e uma determinada fraternidade é o seu código de nascimento, que o vincula a uma obediência em troca da cidadania, de modo que, quando vinculado, se pode ser, em caso de transgressão, no máximo, criminoso, mas nunca inimigo. ${ }^{7}$ Isto ocorre porque, justamente por conhecer a lei em toda a sua validade, o inimigo rouba e depois foge. Ele sabe que praticou um ato contrário às regras sociais de seu grupo e, por isso, se esconde (RESTA, 2005, p. 99).

Essa vinculação entre os homens através da obediência às regras $e$, por conseguinte, da cidadania, é discutida por Zygmunt Bauman (2004, p. 148) quando ele aponta para a produção industrial, na era moderna, de "lixo humano", dos criminosos sociais, especialmente em dois ramos: a) na função de produção e reprodução da ordem social (desse modo, o modelo de ordem é seletivo e exige que se "cortem, aparem, segreguem, separem ou extirpem partes da matéria prima humana que sejam inadequadas para a nova ordem incapazes ou desprezadas para o preenchimento de qualquer de seus nichos"; essas partes assim desprezadas emergem como "lixo", sem utilidade); b) num segundo momento, vislumbra-se o progresso econômico, que exige "incapacitação, o desmantelamento e a aniquilação final de certo número de formas e meios de os seres humanos ganharem a vida - modos de subsistência - que não podiam e nem iriam ajustar-se a padrões de produtividade e rentabilidade em constante elevação." A esses indivíduos foi negado o acesso aos modos de subsistência na medida em que novos arranjos se fizeram necessários, tornandose o "lixo do progresso econômico".

"Il nemico interno viene metabolizzato e neutralizzato attraverso la sua trasformazione in criminale, il nemico esterno rimane potenzialmente tale. La fraternità si chiude nelle patrie piú o meno piccole degli stati-nazione e il diritto internazionale continua a essere il luogo della fraternità variabile e passegera nei confronti di stati che, quando non siano nemici, sono neutri, alleati o destinatari di interferenze paternalistiche." (RESTA, 2007, p. 590). 
Paralelamente, a indústria do lixo humano precisou encontrar formas de lidar com seus rejeitos. Assim, os excedentes da humanidade foram depositados em grandes aterros sanitários, fazendo surgir um novo personagem: o "ser humano lançado além dos limites das leis humanas e divinas", transformando-o num ser ao qual "as leis não se aplicam e cuja destruição não acarreta punições, despida que é de qualquer significado ético religioso". Nesse momento, os direitos humanos desses seres deslocados, tratados como criminosos, mostraram-se terra inóspita, uma vez que não podiam alcançar pessoas que não eram cidadãs de nenhum Estado moderno.

Assim, tomando por pressuposto o fato de que o Estado moderno é um Estado que faz do nascimento 8 o sustentáculo de sua soberania, para que um excluído possa bater a porta do Estado pedindo admissão, ele precisa, primeiramente, ser submetido ao ritual do desnudamento, uma vez que "a nudez da criança recém-nascida ainda não envolta nos ordenamentos jurídico-legais, fornece o lócus em que a soberania do poder do Estado é perpetuamente construída, reconstruída e assistida com o auxílio de práticas de inclusão/exclusão destinadas a todos os outros demandantes da cidadania que caem sob o alcance dessa soberania". Então, para que possam passar a pertencer a determinado Estado, e com isso ser incluído, é preciso primeiro ser excluído, de forma violenta, passar pelo "lugar de nenhum", ser isolado, ficar nu, para só depois vestir as roupas dos iguais e ser incluído no grupo através do código de vinculação (BAUMAN, 2004, p. 150-154).

Nesse sentido, o código de vinculação moderno é o da Revolução Francesa, que determina a igualdade de todos os cidadãos perante a lei, fomentando o nascimento de constituições que davam formulações jurídicas à fraternidade. Isto posto, "a fraternidade das constituições convencionalmente votadas reabre o jogo da amizade política, mas, obviamente, não elimina seus paradoxos." Dentre esses paradoxos, temos que o direito fraterno, constituído entre "iguais deve pressupor um ato originário de supressão do pai, a fim de que não existam mais tiranos, e que, por conseguinte, traz consigo esta teologia da violência", num segundo momento, "diz respeito a razão de ser da vontade geral, que acaba, inclusive em relação a quem dela foi vítima, generalizando a força que vence ou a maioria que a sustenta" (RESTA, 2004, p. 35-36).

Enriquez (1993, p. 312) vê com ceticismo o que ele chama de amor mútuo (na fraternidade), não concordando com a possibilidade de um poder partilhado pela adesão de objetivos traçados para garantir a um grupo a não manifestação de potência de um indivíduo ou subgrupo. Sustenta sua alegação dizendo que se, efetivamente, o vínculo social é um vínculo trágico, e questiona: como seria resolvida (no direito fraterno) a questão da violência interna do grupo? De outra banda, salienta que a vontade coletiva precisa ser expressa pela maioria ou por seus representantes, e precisa prever a aceitação incondicional das diferenças, uma forte capacidade de comunicação e, finalmente, certa comunidade de cultura.

Consequentemente, para Enriquez (1993, p. 317), se o grupo não consegue grau de implicação suficiente para atingir as metas anteriormente traçadas, os membros tenderão a se desligarem. Mas, ao mesmo tempo, questiona: "somos então obrigados a condenar, definitivamente as tentativas de transformação e renovação social?" E responde: "de maneira alguma, muito pelo contrário. Apenas quisemos destacar as pedras e obstáculos inerentes a todo trabalho dessa ordem e dissipar a ilusão... da criação de uma sociedade transparente onde os conflitos encontrariam sempre uma solução..." É por isso que, mesmo mantendo algumas reservas quanto à fraternidade, Enriquez reconhece sua importância como caminho para compreender melhor o funcionamento social afirmando que não devemos esperar uma resposta para a interrogação e sim uma nova interrogação.

\footnotetext{
Hannah Arendt (2004, p. 16-17) aborda as três atividades e suas respectivas condições, que têm íntima relação com as condições mais gerais da existência humana: "o nascimento e a morte, a natalidade e a mortalidade. O labor assegura não apenas a sobrevivência do indivíduo, mas a vida da espécie. $O$ trabalho e seu produto, o artefato humano, emprestam certa permanência e durabilidade à futilidade da vida mortal e ao caráter efêmero do tempo humano. A ação, na medida em que se empenha em fundar e preservar corpos políticos, cria a condição para a lembrança, ou seja, para a história... Não obstante, das três atividades, a ação é a mais intimamente relacionada com a condição humana da natalidade; o novo começo inerente a cada nascimento pode fazer-se sentir no mundo somente porque o recém-chegado possui a capacidade de iniciar algo novo, isto é, de agir".
} 


\section{Giorgio Agamben e a "comunidade que vem": a amizade como "com-sentimento" do puro fato de ser}

A crítica de Hannah Arendt à construção histórica dos direitos humanos, acima apresentada, evidencia, segundo Pérez (2010, p. 48), que, em essência, todo regime político (democrático ou totalitário) fundamenta sua soberania na possibilidade de decisão acerca de quem pertence ou não à comunidade - o que implica definir quem é o amigo e quem é o inimigo e, consequentemente, quem merece viver e quem merece morrer. Para a autora, todo Estado "necessita desplegarse como máquina gubernamental para poder produzir zonas de excepción, de vida nuda, para poder distinguir a cada instante bíos y zoé." (PÉREZ, 2010, p. 48). Essas cesuras são imprescindíveis - como sinaliza a obra de Bauman, referida no tópico precedente - para a configuração daquilo que se poderia chamar de "estoque" de "vidas nuas", ou seja, que estejam dispostas a converter-se em qualquer forma de vida social e politicamente funcional. A figura do Estado - e o seu poder de fazer viver e morrer - ocupa, neste cenário, papel central.

Na leitura de Ferrajoli (2010, p. 118), a cultura contemporânea dos direitos humanos tem se olvidado de suas origens "pouco luminosas". De acordo com o autor, os chamados "direitos universais" - a exemplo do peregrinandi, migrandi, degendi - foram proclamados como iguais e universais apenas em abstrato, mesmo sendo concretamente desiguais e assimétricos, uma vez que, à época, serviram para legitimar a ocupação colonial e a guerra de conquista de novos territórios por parte dos jovens Estados nacionais europeus. Isto explica porque, contemporaneamente, tais direitos têm sido sistematicamente negados à medida que se convertem em direitos de cidadania, ou seja, exclusivos e privilegiados, próprios de quem detém esse status - o de cidadão.

O movimento apreendido pela obra de Hannah Arendt se torna evidente: por meio das declarações de direitos, o "súdito" se transforma em "cidadão", de modo que, com o seu nascimento, marca-se a inscrição da sua vida nua na lógica da soberania. Por esse viés, as declarações de direitos fundamentais, ao lado da sua função emancipatória, cumprem também com a função de "abandono" da vida nua à violência dos mecanismos de poder (AGAMBEN, 2010).

Esse panorama nada alentador pressupõe uma ruptura paradigmática no sentido do estabelecimento de uma vida em comunidade que esteja além, e que supere, definitivamente, a lógica da soberania. Essa guinada requer o estabelecimento de uma entidade sem soberania, considerando-se que o movimento soberano original sempre implica a distinção entre bíos e zoé, ou seja, entre a vida politicamente qualificada e a vida nua. Nesse sentido, seria possível falar em uma comunidade com possibilidade de superar essa cesura entre vidas que merecem ser vividas e vidas que podem ser impunemente eliminadas em virtude de seu caráter efetivamente positivo e não excludente (PÉREZ, 2010, p. 48).

É a partir deste background que Giorgio Agamben (2013) busca estabelecer uma noção de comunidade alijada de qualquer fator negativo. Por meio de "pequenos enunciados, anúncios ligeiros, interrupções, saltos, lacunas e silêncios, às vezes em forma de parábolas, provocações paradoxais, outras vezes através de repetições de temas" (SEDLMAYER, 2008, p. 140), em sua acepção de "comunidade que vem", o filósofo italiano vislumbra espaço apenas para a inclusão, para o pertencimento, para as múltiplas possibilidades.

Trata-se de uma obra que representa a contribuição filosófica agambeniana para um debate que já estava em curso, no cenário francês, desde a década de 1980, a partir do episódio da queda do muro de Berlim e da derrocada do socialismo real. De acordo com Salvetti $(2014$, p. 52) "o fim das políticas comunitárias parecia ter possibilitado a liberdade", e "aquilo que se tinha experimentado foi violência, intolerância contra as diferenças e a multiplicidade”, razão pela qual, em face deste cenário, surgem, na França, intelectuais - como Jean-Luc Nancy e Maurice Blachot - que visavam a uma retomada do ideal político comunitário partindo da tese de que esse projeto, quando "posto em prática, havia produzido violência contra as diferenças, mas ao mesmo tempo não podiam negar que o individualismo egoísta do liberalismo eliminava qualquer possibilidade de solidariedade". Nesse sentido, Nancy é responsável pela obra La comunità inoperosa, na qual se opõe "tanto às soluções do comunismo e fascismo como à hegemonia do 
liberalismo", a qual encontra, na obra de Blanchot, intitulada La comunità inconfessabile, uma resposta. Em sua "Comunidade que vem", Agamben absorve influências de ambos os autores (SALVETTI, 2014, p. 52).

A comunidade, na perspectiva agambeniana, é expropriada de questões identitárias e se apropria do pertencimento no seu sentido puramente existencial. Nesse sentido, o "qualquer" é mencionado "não em termos minoritários ou relacionados a processos identificatórios, mas sim em sua cabal singularidade". Esta, por sua vez, "não se associaria [...] nem ao particular nem ao universal; seria insubstituível, indeterminável, marcada pela diferença". Assim como ocorre na operação de exemplificar, "o qualquer seria uma espécie de exemplo: aquilo que é definido por nenhuma propriedade, exceto o ser-dito" (SEDLMAYER, 2008, p. 141-142). Na expressão de Ramos (2018, p. 4-5),

[...] nem universal nem particular, o exemplo é um objeto singular que se faz ver o ser como tal em sua singularidade. [...] $O$ exemplo não tem outra definição senão a de ser-dito, e tal possibilidade funda todo pertencimento possível e pode por isso questionar todo pertencimento. O ser-dito é aquilo que é radicalmente comum, mas que rompe com toda comunidade real.

A partir da abordagem de Agamben, perde sentido, antes de tudo, qualquer dicotomia do tipo inclusão/ exclusão, que é desativada e transformada em obsoleta na busca por aceder a uma nova política que se encontra assentada sobre a lógica da amizade. Nesse sentido é que, em um de seus ensaios, Agamben faz uma interessante e peculiar leitura da obra aristotélica ao afirmar que a sensação de existir pressupõe "uma outra sensação, especificamente humana, que tem a forma de um com-sentir (synaisthanesthai) a existência do amigo." Para o autor, "a amizade é a instância desse com-sentimento da existência do amigo no sentimento da existência própria", o que "significa que a amizade tem um estatuto ontológico e, ao mesmo tempo, político. A sensação do ser é, de fato, já sempre dividida e com-dividida, e a amizade nomeia essa condivisão." (AGAMBEN, 2009).

Na perspectiva de Agamben (2013) o que assume posição central - e essencial - é o fato de a comunidade humana ser definida, em relação à comunidade animal, por meio de um conviver que não é definido pela participação em uma substância comum, mas por uma "condivisão" puramente existencial e, por assim dizer, sem objeto. Os amigos não "condividem" algo (um nascimento, uma lei, um lugar, um gosto): eles são "com-divididos" pela experiência da amizade. Isto significa que a amizade é a "condivisão" que precede toda divisão, porque aquilo que há para repartir é o próprio fato de existir, a própria vida.

O indivíduo, nesse marco, não precisa cumprir com nenhum requisito, elaborar nenhuma justificativa, senão somente "ser tal qual é". Daí a afirmação de Agamben (2013, p. 09) no sentido de que "o ser que vem é o ser qualquer", ou seja, a única divisão admissível em uma comunidade é a divisão puramente existencial. Não se admite, aqui, divisões e partilhas de classes de fundação comunitária (por exemplo, lugar de nascimento, língua, raça, etc.) ou a ausência genérica de condições de fundação (comunidade negativa). Nesse contexto, a singularidade não implica

[...] ter esta ou aquela propriedade, que identifica uma pertença a um determinado conjunto, ou a uma determinada classe (os vermelhos, os franceses, os mulçumanos). O ser-qual não é um predicado real, mas sim a pura afirmação do ser-tal. Este 'ser tal' permanece constantemente escondido na condição de pertencimento: a sentença "existe um x tal que pertence a ' $y$ ', de modo que o 'tal que' não indica uma propriedade, mas, antes, visa revelar a própria lógica do pertencimento. Assim, não se trata de colocar o ser-qual qualquer em uma outra classe ou conjunto, a saber, a classe daqueles que não tem classe, mas antes revelar a dimensão da singularidade que, como tal, coloca em questão o próprio pertencimento (RAMOS, 2018, p. 04).

O personagem da literatura de Herman Melville - o escrivão Bartleby - é empregado por Agamben para demonstrar essa condição: assim como Bartleby pode escrever ou não e, dessa forma, possuir a experiência da linguagem, "o ser qualquer é aquele que também pode ser impotente, inoperante." Isto porque a "exposição da inoperância [...] é associada por Agamben a uma espécie de ócio sabático, a ausência de trabalho produtivo." (SEDLMAYER, 2008, p. 143). Nesse sentido, pode-se afirmar que o caráter potencial da singularidade qualquer não reside em ser a potência deste ou daquele ato específico; antes, ela abarca a própria potência enquanto tal. Com efeito, "a potência da singularidade qualquer é a potência do não, 
ou seja, o ser que pode não ser. Em outras palavras, a singularidade é a potência que pode a própria impotência." É exatamente por isso que "Bartebly, que nunca deixa de escrever, mas, "preferiria não fazêlo', encarna a potência que se pensa a si mesma." (RAMOS, 2018, p. 08).

Assim como o ser - qualquer -, deve-se propugnar por uma comunidade que vem: esta não é a comunidade que virá, mas a comunidade que nunca chega, que está em constante devir, que nunca acaba de chegar. Uma comunidade que vem - e que, por consequência, jamais termina de chegar - se afigura, nesse contexto, enquanto condição de possibilidade para que se possa evitar a expressão soberana por excelência e as censuras que lhe subjazem: distinções entre o que está dentro e o que está fora, entre o que é próprio e o que é estranho, entre nacionais e estrangeiros, amigos e inimigos, enfim, entre zoé e bíos. Como assevera Pérez (2010, p. 48), uma comunidade que nunca termina de chegar também nunca está o suficientemente acabada para dar lugar a tal movimento soberano.

A comunidade que vem, nesse sentido, só pode ser uma comunidade na qual a política é a amizade, ou seja, a "com-divisão" da própria existência. O ser que vem, então, é aquele que permanece, ao mesmo tempo, aberto e singular. Ele se funde no geral, preservando sua singularidade. Em síntese, é o ser inacabado, aberto a outras possibilidades. Esse ser amável definido por Agamben (2013) é o ser com todos os seus predicados, o ser tal qual é.

Com efeito, o amor não se dirige apenas a algumas peculiaridades do ser amado (características físicas ou psicológicas específicas, por exemplo), tampouco prescinde dessas particularidades em nome de uma insípida generalidade (amor universal): ele quer o ser com todos os seus predicados, ou seja, "tal qual é". Desse modo, "a singularidade qualquer (o Amável) não é jamais inteligência de alguma coisa, desta ou daquela qualidade ou essência, mas somente inteligência de uma inteligibilidade" (AGAMBEN, 2013, p. 11). De acordo com Agamben (2013, p. 11), "as minhas qualidades, o meu ser-assim não são qualificações de uma substância (de um sujeito) que permaneça atrás delas, e que eu verdadeiramente seria. Eu não sou jamais isto ou aquilo, mas sempre tal, assim. Eccum sic: absolutamente. Não posse, mas limite; não pressuposto, mas exposição."

Ser tal-qual, ${ }^{9}$ sem deixar de estar exposto a ser de outra maneira, é o que revela, segundo o autor, o milagre do mundo. ${ }^{10}$ Esse "ser tal qual" - do mundo e de todo o ser - é o "irreparável"; ${ }^{11}$ aquilo que é assim e não de outra maneira, mas que está exposto a ser de qualquer outra forma. Somente a partir do momento em que o "irreparável do mundo" é percebido, ou seja, em que as coisas em sua exposição sejam como são, é que se torna possível a salvação, uma salvação imanente que implica, antes de tudo, uma comunidade sem soberania: trata-se da salvação do caráter profano do mundo.

Nesse rumo, "ser tal qual" é ser exposto, o que significa uma vida sempre aberta a tomar esta ou aquela forma, mas sem jamais consolidar-se de maneira permanente em uma forma de vida dada, senão ser "forma-de-vida". Dito de outra forma: em oposição às diversas formas de vida codificadas socialmente, a forma-de-vida é aquela que não demanda a separação entre zoé e bíos: ela conserva a potência e se encontra aberta a ser de qualquer forma. Nas palavras de Agamben (2015, p. 13), a expressão forma-devida designa "uma vida que jamais pode ser separada de sua forma; uma vida na qual jamais é possível isolar alguma coisa como uma vida nua."

Trata-se, aqui, segundo Pérez (2010, p. 49), de uma vida que conserva sua abertura, ou seja, sua exposição. Nesse sentido, em uma comunidade sem soberania, a separação entre zoé e bíos é absolutamente improcedente, visto que a bíos conserva a abertura e a exposição da zoé.

\footnotetext{
9 "Tal qual. Aqui a anáfora tal não remete a um termo referencial precedente (a uma substância pré-linguística) e qual não serve para identificar um referente que dê ao tal o seu sentido. O qual não tem outra existência a não ser o tal, e o tal não tem outra essência a não ser o qual. Eles se contraem um sobre o outro, se expõem mutuamente, e o que existe é o ser-tal, uma tal qualidade absoluta, que não remete a nenhum pressuposto." (AGAMBEN, 2013, p. 90).

10 Segundo Agamben, "talvez o único modo de compreender esse livre uso de si, que não dispõe, porém, da existência como de uma propriedade, é o de pensá-lo como um hábito, um ethos. Ser gerado a partir da própria maneira de ser é, de fato, a definição mesma do hábito (por isso os gregos falavam de uma segunda natureza): ética é a maneira que não nos ocorre nem nos funda, mas nos gera. E esse ser gerado pela própria maneira é a única felicidade verdadeiramente possível para os homens." (AGAMBEN, 2013, p. 35).

11 Como esclarece Agamben (2013, p. 43-44), "irreparável significa que elas [as coisas] são consignadas sem remédio ao seu ser-assim, que elas são, antes, precisamente e somente o seu assim [...]; mas significa, também, que, para elas, não há literalmente nenhum abrigo possível; que, no seu ser-assim, elas estão agora absolutamente expostas, absolutamente abandonadas."
} 
Trata-se, em suma, de se pensar para além do sujeito, de se pensar uma "singularidade qualquer (quodlibet)" (AGAMBEN, 2013). A resolução do nexo entre lei e vida só é possível a partir dessa forma-devida que veda qualquer distinção entre zoé e bíos. Unidas, zoé e bíos se apresentam como condição de possibilidade para a superação do bando soberano. Afinal,

[...] apenas se eu já não estou sempre e somente em ato, mas sou entregue a uma possibilidade e a uma potência, apenas se, nas minhas vivências e nos meus entendimentos, estão sempre em jogo o viver e o entender eles mesmos - ou seja, se há, nesse sentido, pensamento -, então uma forma de vida pode tornar-se, em sua própria facticidade e coisalidade, forma-de-vida, na qual nunca é possível isolar algo como uma vida nua (AGAMBEN, 2015, p. 19).

Enquanto devir perene, a comunidade se opõe a qualquer forma de acabamento, o que suscita a questão sobre como escapar à concreção do processo e permanecer como abertura às possibilidades. Assume relevância, então, a ideia de inoperosidade cunhada por Agamben e que serve como resposta à objeção. Aqui, a saída não reside em uma potência que nunca passa ao ato. Pelo contrário, ela pressupõe uma potência que, ao passar ao ato, sobrevive nele, pois suas possibilidades não se esgotam no ato, mas permanecem apesar do ato.

É importante destacar que o poder de não ser não se afigura enquanto mera passividade. Ele é considerado um poder verdadeiro, uma potência negativa que se esforça em não se esgotar, em não se concretizar; nem em sua total negação, nem em sua total afirmação.

Assim como é capaz de ser, este poder é capaz de não ser. Como salienta Agamben (2013, p. 40), "somente uma potência que pode tanto a potência quanto a impotência é, então, a potência suprema. Se toda potência é tanto potência de ser quanto potência de não ser, a passagem ao ato só pode advir transportando [...], no ato, a própria potência de não ser."

Nesse ponto, deve-se compreender que a noção de inoperosidade agambeniana não está relacionada à ideia de levar algo à inércia, à ineficácia. Pelo contrário, o autor preocupa-se em pensar uma categoria que viabilize um novo uso do que é posto em inoperosidade, razão pela qual "o movimento que torna inoperoso deve portanto deixar a potência intacta, cancelando somente as finalidades e as modalidades nas quais o seu exercício era investido." (NASCIMENTO, 2012, p. 220). Dessa forma, as funções de uso do que é conduzido à inoperosidade sofrem uma considerável variação, mas não se anula inteiramente a possibilidade de usar.

Em Agamben (2013, p. 103), "inoperosidade não significa inércia, mas katargesis - isto é, uma operação na qual o como substitui integralmente o que, na qual a vida sem forma e as formas sem vida coincidem em uma forma de vida." Assim, pode-se acrescentar que "a inoperosidade sugere um modo diverso de ser, um modo diverso de agir e de viver, ainda que isso determine apenas a transformação do mesmo." (NASCIMENTO, 2012, p. 220). ${ }^{12}$

O conceito de inoperosidade, portanto, se mostra fundamental para que se possa pensar em uma forma de se desarticular a relação entre direito e violência, de modo a desativar e tornar inoperosos os dispositivos que viabilizam o aprisionamento do homem às redes biopolíticas da contemporaneidade; daí a afirmação de Agamben (2011) no sentido de que nada é mais urgente do que a inclusão da inoperosidade nos próprios dispositivos. ${ }^{13}$

Nascimento (2012, p. 220) utiliza-se, aqui, de um elucidativo exemplo para a compreensão da ideia de inoperosidade segundo Agamben: "um mesmo gesto, dependendo das circunstâncias em que é praticado, pode possuir uma natureza ou outra: numa festa entre os funcionários de um restaurante realizada depois do expediente de trabalho, aquele que serve a mesa passando a bandeja não o faz pelo dever de ofício, mas num gesto de pura gratuidade. O agir humano tornado inoperoso é suspenso na sua economia."

13 É importante observar, aqui, que Agamben retoma o termo "dispositivo" da obra de Foucault para ampliá-lo e elevá-lo à categoria fundamental para compreensão do mecanismo político contemporâneo. Assim, dispositivo é considerado pelo autor como "qualquer coisa que tenha de algum modo a capacidade de capturar, orientar, determinar, interceptar, modelar, controlar e assegurar os gestos, as condutas, as opiniões e os discursos dos seres viventes. Não somente, portanto, as prisões, os manicômios, o Panóptico, as escolas, a confissão, as fábricas, as disciplinas, as medidas jurídicas etc., cuja conexão com o poder é num certo sentido evidente [conforme a noção foucaultiana do termo], mas também a caneta, a escritura, a literatura, a filosofia, a agricultura, o cigarro, a navegação, os computadores, os telefones celulares e - por que não - a própria linguagem, que talvez é o mais antigo dos dispositivos, em que há milhares e milhares de anos um primata - provavelmente sem se dar conta das consequências que se seguiriam - teve a inconsciência de se deixar capturar." (AGAMBEN, 2009, p. 40-41). 
Nesse rumo, pode-se afirmar que a superação da soberania não somente implicaria chegar a uma comunidade na qual é impossível a cisão entre zoé e bíos e, por consequência, não existe a figura da exceção. Em um modelo tal, tudo é pertencimento e se tornam absolutamente desnecessário o isolamento e a divisão. Nesse modelo, é possível, então, "ser tal qual é", ou seja, ser pura exposição, possibilidade que se nega a assumir uma forma de vida determinada.

Agamben (2012) assevera que a vida nua foi, paradoxalmente, excluída da política e, concomitantemente, incluída e capturada através da sua exclusão, o que significa que a vida nua pode ser compreendida enquanto o fundamento negativo do poder. Na biopolítica moderna, essa separação atinge sua forma extrema: o cuidado e a decisão sobre a vida nua se tornam aquilo que está em jogo na política. Isto fica muito evidente a partir do que aconteceu nos estados totalitários do século XX: em todas essas experiências, o poder (que também assume a forma da ciência, como no exemplo do nazismo) é quem decide, em última análise, sobre o que é uma vida humana e sobre o que ela não é. É por isso que o autor propõe "pensar numa política das formas de vida, a saber, de uma vida que nunca seja separável da sua forma, que jamais seja vida nua." (AGAMBEN, 2008).

Segundo a perspectiva agambeniana, "a tarefa que nos espera consiste, portanto, em pensar integralmente, de cabo a cabo, aquilo que até agora havíamos definido com a expressão, de resto pouco clara em si mesma, 'vida política'" (AGAMBEN, 2012). Em outras palavras, é possível, então, asseverar que Agamben nos convida a reexaminar as bases da autoridade jurídico-política para, ao invés de justificar o poder soberano, conceber uma comunidade política que não o pressupõe. Agamben projeta uma comunidade que está além da tradição da soberania. $O$ abandono das narrativas patrióticas e uma inextrincável relação entre política e subjetividade se impõem.

\section{Considerações Finais}

Na contemporaneidade, fica cada vez mais evidente a construção de concepções de amigo/inimigo/ criminoso/estrangeiro no Direito e também na política, uma vez que, dentro de um mesmo Estado - numa concepção geopolítica -, podem existir, além do amigo e do criminoso, também o inimigo, que primeiramente habita outro Estado - reside fora das fronteiras -, mas que estaria aqui representado pelo estrangeiro e pelo excluído. Estes últimos que, muitas vezes sem praticar atos contrários às regras (portanto não são criminosos), se mantêm à margem do sistema social, não são reconhecidos nem considerados. Trata-se de um inimigo/estrangeiro "interno".

Desse modo, o presente trabalho objetivou buscar, nas obras de Jacques Derrida e Giorgio Agamben - pensadores que debatem a amizade e a comunidade como ponto central de suas teorias - um aporte para refletir sobre as diferentes concepções de amizade e comunidade que permeiam seus pensamentos, relacionando-as com tentativas de construção de uma nova perspectiva de análise da temática dos direitos humanos e da construção de pressupostos para uma cultura de paz.

O esquecimento de nossa condição de humanidade, de seres comuns com as mesmas necessidades, e a atribuição ao outro do rótulo de estrangeiro/diferente/inimigo demonstram "o individualismo desencarnado da existência que prescinde, sempre, a presença do outro para nos constituir como identidade" (WARAT, 2004, p. 114).

Esse individualismo se coloca no centro do jogo humano moderno e pode ser se retratado num corpo isolado, sólido, individualizado, daí o jogo de palavras: solidez, solidão e solidariedade. Essas palavras possuem uma raiz comum que remete ao estar só, ilhado, mas que também remete ao caráter compacto e à indivisibilidade.

Verdadeiramente, se tal discussão for direcionada para o mundo jurídico, avista-se um individualismo que se reflete na ideia de um sujeito "isolado". É aqui que se pode retomar a obra cinematográfica referida nas considerações iniciais. Como Antônia não hesita em quebrar pouco a pouco todos os tabus locais, ela alcança a transformação da mentalidade dos habitantes do vilarejo. Ao longo da história, a sua (excêntrica) família/comunidade vai sendo composta como um grupo aberto, formado principalmente pelas pessoas 
excluídas da sociedade - seja por questões psicológicas, cognitivas, seja porque pensavam de modo oposto ao "ethos" cultivado pelos moradores da aldeia -, a exemplo de sua filha, Danielle, que passa a viver uma relação homoafetiva com a professora de sua neta.

As cenas de confraternização de todos ao redor da mesa posta no jardim da casa de Antônia mostram o crescimento da família/comunidade, e significam o renovar da vida do vilarejo, a partir de uma nova lógica: a da hospitalidade, da tolerância às diferenças e do afeto. Antônia arrosta da sua comunidade todos os fatores negativos: nela, tudo é inclusão, pertencimento, propriedade e possibilidade. Não há, na família de Antônia, uma lógica de inclusão/exclusão: ninguém é obrigado a cumprir requisito algum, tampouco justificar-se ou reparar-se. Resta a cada um apenas "ser-tal-qual-é", e é exatamente isto que permite, ao longo da história, o desvelamento das pessoas outrora escondidas pelos estereótipos.

Nesse sentido, este filme se afigura importante para a análise da temática aqui proposta: tal como propõem Derrida e Agamben - a partir de suas diferenças e convergências na abordagem do tema da comunidade, da amizade e da fraternidade -, a história de Antônia e sua excêntrica família revela uma forma absolutamente diferente de abordar as singularidades de cada um, permitindo, desse modo, promover aquilo a que Giuseppe Tosi denomina de "dialética da intersubjetividade, na qual o outro não seja reconhecido como um inimigo, ou seja, como um não eu, mas como outro eu: 'eu mesmo como um outro'". ${ }^{14}$

É nesse sentido que reconhecer o outro como a mim mesmo significa fomentar a dialética da alteridade, alcançando o reconhecimento comum de pertença que faz parte da condição humana. Essa proposta supera a lógica do "pertencimento" para proteger a lógica do "humano", do "estar com o outro", e não "contra o outro".

\section{Referências}

A EXCÊNTRICA família de Antonia. Direção: Marleen Gorris. Produção: Judy Counihan, Antonio Lombardo, Hans de Weers, Bard Entertainment, Bergen Film \& TV e Prime Time. Edição: Wim Louwrier e Michiel Reichwein. [São Paulo: Van Blad], 1995. 1 DVD (102 min.).

AGAMBEN, Giorgio. A comunidade que vem. Tradução: Cláudio Oliveira. Belo Horizonte: Autêntica, 2013.

AGAMBEN, Giorgio. O que é o contemporâneo? e outros ensaios. Tradução: Vinícius Nicastro Honesko. Chapecó, SC: Argos, 2009.

AGAMBEN, Giorgio. Homo sacer: o poder soberano e a vida nua I. Tradução: Henrique Burigo. Belo Horizonte: Editora UFMG, 2010.

AGAMBEN, Giorgio. O reino e a glória. Tradução: Selvino J. Assmann. São Paulo: Boitempo, 2011.

AGAMBEN, Giorgio. "Deus não morreu. Ele tornou-se Dinheiro". Entrevista com Giorgio Agamben.

Instituto Humanitas UNISINOS, São Leopoldo, 30 ago. 2012. Disponível em: http://www.ihu.unisinos.br/ noticias/512966-giorgio-agamben. Acesso em: 23 ago. 2015.

AGAMBEN, Giorgio. O que resta de Auschwitz: o arquivo e a testemunha (Homo Sacer III). Tradução de Selvino J. Assmann. São Paulo: Boitempo, 2008.

AGAMBEN, Giorgio. Meios sem fim: notas sobre a política. Tradução: Davi Pessoa. Belo Horizonte: Autêntica, 2015.

ALBORNOZ, Suzana. Políticas da amizade de Jacques Derrida. In: ALBORNOZ, Suzana; GAI, Eunice Piazza (org.). Ó meus amigos, não há amigos! Reflexão sobre amizade. Santa Cruz do Sul: Movimento/Edunisc, 2010. p. 132-147.

ARENDT, Hannah. Condição humana. Tradução: Roberto Raposo. 10. ed. Rio de Janeiro: Forense, 2004.

14 Essa é a fórmula de Paul Ricoeur (2009). 
ARISTÓTELES. Os pensadores. São Paulo: Nova Cultural, 1996.

BAGGIO, Antonio Maria. O princípio esquecido. São Paulo: Cidade Nova, 2009.

BAUMAN, Zygmunt. Amor líquido: sobre a fragilidade dos laços humanos. Tradução: Carlos Alberto Medeiros. Rio de Janeiro: Jorge Zahar, 2004.

BAUMAN, Zygmunt. Comunidade: a busca por segurança no mundo atual. Rio de Janeiro: Jorge Zahar, 2003.

CANETTI, Elias. Massa e poder. Tradução: Sérgio Tellaroli. São Paulo: Companhia das Letras, 1995.

DERRIDA, Jacques. Política da amizade. Tradução: Fernanda Bernardo. Porto: Campo das Letras, 2003.

DERRIDA, Jacques. Del'hospitalité. Paris: Calmann-Levy, 1997.

ENRIQUEZ, Eugène. Da horda ao Estado: psicanálise do vínculo social. Tradução: Teresa Cristina Carreteiro e Jacyara Nasciutti. Rio de Janeiro: Jorge Zahar, 1993.

FERRAJOLI, Luigi. Derechos e garantias: la ley del más débil. 7. ed. Madrid: Trotta, 2010.

FREUD, Sigmund. O mal estar da civilização. Tradução: José Octávio de Aguiar Abreu. Rio de Janeiro: Imago, 1997.

NASCIMENTO, Daniel Arruda. Do fim da experiência ao fim do jurídico: percurso de Giorgio Agamben. São Paulo: LiberArs, 2012.

ORTEGA, Francisco. Para uma política da amizade: Arendt, Derrida, Foucault. Rio de Janeiro: Relume Dumará, 2000.

PÉREZ, María Luisa Bacarlett. Giorgio Agamben: del biopoder a la comunidad que viene. Araucaria: Revista Iberoamericana de Filosofía, Política y Humanidades, Sevilha, ano 12, n. 24, 2010.

RAMOS, Pedro Hussak Van Velthen. Sobre a comunidade que vem de Giorgio Agamben. In: COSTA, Admar Almeida et al. (org.). Ética e alteridade. Rio de Janeiro: EDUR, [2010]. cap. 10. p. 1-13.

Disponível em: http://www.ufrrj.br/graduacao/prodocencia/publicacoes/etica-alteridade/artigos/Pedro_ Hussak.pdf. Acesso em: 10 abr. 2018.

RESTA, Eligio. II diritto fraterno. Roma-Bari: Laterza, 2005.

RESTA, Eligio. Fraternità. In: FLORES, Marcello; GROPPI, Tânia; MAZZESCHI, Riccardo Pisillo. Diritti umani. Cultura dei diritti e dignità della persona nell'epoca della globalizazione. Dizionario I A-G. Torino: Unione Tipografico Editrice Torinense, 2007.

RESTA, Eligio. Poteri e diritti. Torino: Giappichelli Editore, 1996.

RESTA, Eligio. Le verità e il processo. In: MARINI, Alarico Mariani. Processo e verità. Pisa: Plus, 2004. p. 369-408.

SALVETTI, Ésio Francisco. A comunidade que vem: uma tarefa ética em Giorgio Agamben. Revista Profanações, Mafra, ano 1, n. 2, p. 48-69, jul./dez. 2014.

SCHMITT, Carl. O conceito do político. Petrópolis: Vozes, 1992. (Clássicos do Pensamento Político, 33).

SEDLMAYER, Sabrina. A comunidade que vem. In: PUCHEU, Alberto (org.). Nove abraços no inapreensível: filosofia e arte em Giorgio Agamben. Rio de Janeiro: Beco do Azougue: FAPERJ, 2008. p. 139-148.

TOSI, Giuseppe. A fraternidade é uma categoria política? In: BAGGIO, Antonio Maria. O Principio esquecido. São Paulo: Cidade Nova, 2009. p. 43-64.

WARAT, Luis Alberto. Surfando na pororoca: o ofício do mediador. Florianópolis: Fundação Boiteux, 2004. 3. v. 